Artículo de Reflexión

A puntes del CENES

ISSN 0120-3053

Volumen 32 - №. 56

Julio - Diciembre de 2013

Págs. 81-104

\title{
El euro y el consumidor como fenómenos políticos en el actual desarrollo de Europa.
}

\section{The euro and the consumer as political phenomena in the current development of Europe.}

Guillermo Castro*

Fecha de recepción: 6 de mayo de 2013

Nueva versión: 23 de mayo de 2013

Fecha de aprobación: 31 de mayo de 2013

Abogado de la Universidad Nacional de Colombia; magíster de la Universidad Nacional de Colombia; magíster Llegum, cum Laude de Universität Konstanz; DoktorJuris, Magna cum Laude de la Universität Konstanz, estancia posdoctoral; director del Grupo de Investigaciones en Derecho Privado, GEPPI, de la Universidad Católica de Colombia. Bogotá-Colombia. Correo electrónico: castroayal@gmail.com 


\section{Resumen}

El sistema económico capitalista no levanta cabeza en el mundo entero desde 2008. Pareciera que por lo mismo las instituciones políticas deben procurar encontrar un nuevo marco jurídico para las relaciones económicas. Una pregunta que queda flotando en el ambiente es si las garantías jurídicas se someterán a lo económico o si, por el contrario, la economía se permeará por la prevalencia de los derechos y libertades del sujeto. Para poder hacer una primera aproximación a eventuales respuestas, debe ponderarse el entendimiento del nuevo patrón económico de un mercado trasnacional, por ejemplo el euro, con el dela nueva concepción del sujeto jurídico inmerso en el mismo mercado, esto es, el consumidor. A esa tarea se contrae este artículo en el marco de la Unión Europea.

Palabras clave: Euro, economía del consumidor, sistemas económicos, derecho y economía, Unión Europea.

Clasificación JEL: F33, P10, P00, K10, F02

\section{Abstract}

The capitalist economic systemis not getting off worldwidesince 2008. Soitseems that political institutions should try to finda new legal frame work for economic relations. One question remains unanswered until today: if legal guarantees shall be subject to the economic systemor, other wise, the economy shall be permeated by the prevalence of the rights and liberties of the individual? In order to do a first approach to any answers, we should ponder the understanding of the new economic pattern of a transnational market, for example the Euro, with the new concept of legal subject in the same market, that is, the consumer. This article tries tocover this idea in the European Union framework.

Keywords: Euro, consumer economics, economic systems, law and economics, European Union.

JEL Classification: F33, P10, P00, K10, F02 


\section{INTRODUCCIÓN}

Desde 2008, las noticias sobre la inestabilidad económica mundial despiertan un alto grado de desconfianza en el ciudadano particular. La crisis de los Estados Unidos de Norteamérica, de Grecia, Chipre o España, no dejan de preocupar y de evidenciar una latencia de otra eventual y peor crisis: la caída definitiva del euro o la declaración de recesión norteamericana a largo plazo. Los desahucios españoles y una balanza de pagos del sector público en general en rojo, han implicado la degradación por parte de las calificadoras de riesgo de países como Francia (Rickens, 2012) o Italia y son elementos poco halagüeños a la hora de hablar de una superación de la coyuntura.
Pero más allá de la suerte misma de la crisis, lo que ocupa en mayor medida las reflexiones de la gente del común, es hasta qué punto va a haber restricciones de derechos y ventajas sociales, culturales y económicas. Nadie quisiera estar en los zapatos de un parado o de un desahuciado español y menos en los de un desempleado griego o del estado de Carolina del Norte en USA ${ }^{1}$. Hasta dónde se van a respetar pues los pactos constitucionales y los derechos económicos en ellos contenidos. ¿Deberán los derechos sociales y en general el constitucionalismo nacional seguir cediendo ante el imperio del mercado trasnacional o ha llegado el momento de replantear la globalización neoliberal impuesta desde 1980 para muchos países?

\footnotetext{
Entre los más recientes análisis sobre el mayor endeudamiento de Grecia, España e Italia en Europa en los últimos doce meses, véase: Frankfurter Allgemeine (2013, 22 de abril).

Así mismo, sobre la aguda crisis en algunos de los estados de Norteamérica, sobre la que ya se predica el desafió de la ruptura entre ricos y pobres, véase: Buchter (2012).
} 
Un escenario que posibilita una primera aproximación a esas respuestas, surge del análisis de los dos polos kantianohegelianos de las relaciones sociales; esto es, el "sujeto-objeto" en el principal mercado trasnacional que existe hasta ahora en el planeta: la Unión Europea. Muy probablemente la suerte que corran tanto la moneda o el particular en el constitucionalismo europeo, del que desde 1991 somos epígonos tangenciales, va a terminar influenciando el discurrir del mismo equilibrio nacional en muchas otras latitudes.

En ese orden de ideas, tratando de buscar arquetipos omnicomprensivos de la problemática bipolar descrita, tras releer los lineamientos de la teoría sistémica social expuesta por Niklas Luhmann, se puede concluir que la Unión Europea es ese laboratorio sistémico, en que se ha materializado cada una de sus palabras y quien ya pronto en sus trabajos, entre otras cosas, visualizó un único Estado europeo (Zorn, 2010; Luhmann, 1998).

En este proceso reconocido y avizorado por Luhmann, la cuarteta conformada por los subsistemas: jurídico, económico, político y cultural, se recrea y se confronta permanentemente, para lograr, en teoría, un equilibrio de fuerzas que está al servicio del máximo bienestar, tanto del individuo como de la sociedad, y en cuyo estadio ideal podrán ser alcanzadas mejores prerrogativas (jurídicas) para los particulares y muchos más privilegios aún (incluso económicos) para el sistema omnicomprensivo, esto es, para la Unión Europea misma.

Teniendo como punto de partida la existencia iconográfica de esos subsistemas inmersos en un sistema superior de la teoría luhmanniana, es necesario reconocer que de manera complementaria, pero también contraria a la división de poderes tradicionalmente defendida desde la perspectiva nacional liberal $^{2}$, a su vez pueden reconocerse en el renovado Estado europeo "unityinputs" (Luhmann, 1998) ("emisiones unificadoras" en español), que en principio no dividen los poderes políticos, sino que los concentran, a efectos de mantener cohesionado el sistema. Esos inputs, siempre emitidos desde alguno (o algunos) de los subsistemas, repercuten sobre la totalidad de la sociedad, esto es, sobre el sistema pleno, en nuestro caso, sobre la Unión Europea.

Vale la pena tratar dos elementos integrantes del mercado común europeo, entendidos como algunos de esos inputs. En concreto, me referiré a una emisión realizada desde el subsistema económico europeo para la Unión, específicamente al "euro" y a otra emisión incorporada a su vez por el subsistema jurídico europeo,

\footnotetext{
Así, por ejemplo, las ya clásicas divisiones en poder ejecutivo, legislativo y judicial nacionales, pero también pueden tenerse en cuenta las así llamadas «divisiones transversales de poderes» en la Suprafederación Europea, donde, por ejemplo, el Parlamento Europeo puede articular con los ejecutivos nacionales y con las jurisdicciones comunales, la aplicación del derecho en determinada área.
} 
el "consumidor", entendido como " $e l$ sujeto" del mercado común. Esos dos elementos los abordaré por supuesto desde el enfoque normativista que subyace en lo jurídico.

\section{EL EURO Y EL CONSUMIDOR COMO ELEMENTOS DEL MER- CADO COMÚN EUROPEO}

Sin detenernos en complejidades técnicas económicas, se puede en general entender la economía de mercado como la organización encaminada a la asignación eficiente de la producción y al máximo aprovechamiento de bienes y servicios (Rey, 2003). Desde el funcionalismo predicado por T. Parsons (Parsons, 1991, p. 2), en la acción marco de referencia,se pueden reconocer dos elementos que a la postre siempre intervienen jurídica y contablemente en todos los intercambios onerosos: idealmente, siempre dos sujetos concurren a negociar dos objetos que de consenso entre ellos son intercambiados (permutados, si se quiere). Pues bien, el objeto por antonomasia en el mercado, es el dinero circulante, $\mathrm{y}$, de hecho,es a través de él, que de manera ideal se cuantifica la riqueza, dentro del mismo mercado $^{3}$. De alguna manera, si se quiere, los subsistemas jurídico-privado y económico se articulan a través del dinero. A su vez, el mejor ejemplo de los sujetos es el homo oeconomicus, esto es, el individuo,el sujeto jurídico por excelencia: la persona natural, de la cual se ocupa el derecho civil de las personas en todas las culturas occidentales.

En este ejercicio de reducción de la complejidad teórica, en general,podría decirse que hay un consenso entre los economistas, en cuanto a que de cualquier mercado moderno podría ser eliminada cualquier otra variable, pero no podría prescindirse del binomio: sujeto-dinero. Estos ejercicios han sido conocidos como "subjetivismo en la teoría social económica" y obedecen fundamentalmente a que sin estos, los dos elementos que definen el mercado, resulta imposible sostener cualquier clase de raciocinio. Puesto de otra manera: sujeto y dinero son los elementos estructurales del mismo. (Zwiedineck, 1955, p. 372)

A continuación trataré de analizar cada uno de esos elementos en la compleja dinámica de la Unión Europea e intentaré describir como desde una lectura políticamente orientada, ellos pueden ser concebidos, en no pocas oportunidades, como fuerzas antagónicas. Desde este ángulo, resulta necesario asumir que, por un lado, el derecho del consumo ha modificado significativamente la configuración de poderes en el interior de la Unión Europea, al paso que el euro ha hecho lo propio con el papel de la misma Unión, en la geopolítica mundial, pero desde una perspectiva económica.

$3 \quad$ Cfr Mises, Part one, The nature of Money (1953). 
La tesis que voy a defender es que esos dos elementos, por lo menos desde mi espectro de investigación, son indispensables para terminar de entender algunas configuraciones específicas que ha adquirido la cada vez más compleja organización política europea; y claro está, también algunas recientes decisiones incorporadas en el Tratado de Lisboa, sobre el Mercado Común Europeo. Esas reflexiones podrían dar señales sobre cuál de los dos elementos podría llegar a prevalecer en el futuro: el dinero o el sujeto particular, inmerso en el mercado, que debe -en todo casoperpetuarse como un mercado constitucional.

\section{El euro}

En el año de 1957, la naciente Comunidad Económica Europea decidió, entre otros puntos, mediante el Tratado de Roma, crear un mercado común europeo. Así, se estableció un mercado y aranceles externos comunes, una política conjunta para la agricultura, políticas comunes para el movimiento de mano de obra y para la infraestructura de los transportes. Igualmente decidió fundar instituciones comunes para el desarrollo económico, las cuales se fusionaron en el año de 1965 con las instituciones de la CECA y las de la EURATOM, gracias al Tratado de Bruselas 5 .
Es por todos conocido que las obligaciones derivadas para los Estados signatarios y adherentes a esas convenciones, permanecieron, sin embargo, parcialmente en la esfera del derecho internacional público, a la vera de múltiples procesos políticos, como la guerra fría, un lento pero perceptible fortalecimiento constitucional de las democracias europeas, así como entre otros a la deriva de un avance tecnológico de ritmos y velocidades nunca antes conocidos. Los pactos internacionales se veían durante esa época, un poco más como "el aseguramiento de los territorios", que como obligaciones político económicas seriamente adquiridas. Se podría decir que solo hasta la década del noventa se siente la plena eficacia y los efectos tangibles derivados de esos acuerdos (Stöver, 2007, p. 48 y ss.)

\section{Breve historia del euro}

Es evidente que procesos como la unificación alemana, la perestroika y el así llamado Glasnost aceleraron la concreción de las que permanecían como incipientes buenas intenciones diplomáticas en Europa (Stöver, 2007, p. 437 y ss.) Es así como a través del Tratado de Maastricht, se acuerda la creación de una moneda única en el año de 1993, que recibe el 15 de diciembre de 1995 el nombre de "euro" en la capital española, y que solo hasta el $1^{\circ}$ de enero de 1999 entra en circulación en los doce países que se acogieron al "Plan de Unificación

\footnotetext{
Sobre la historia y la preparación del Tratado de Roma, consultar: CVCE (2012).

5 Ese documento se conoce como la versión consolidada del Tratado de la Unión Europea, que por supuesto ha tenido modificaciones con Maastricht y Lisboa, entre otros, al respecto ver: Diario Oficial de la Unión Europea (1965).
} 
Monetaria", de los dieciséis que para entonces conformaban la Unión. Obstáculos técnicos atinentes al perfeccionamiento de la seguridad en la acuñación del nuevo circulante, implicaron la permanencia de los antiguos valores nacionales como medios de pago, durante un tiempo posterior; pero de manera general puede afirmarse que a partir del $1^{\circ}$ de enero de 2002 , el euro fue reconocido ya como el único medio de solución válida de las obligaciones dinerarias, dentro de las fronteras de la Eurozona. (Euroinphoto.eu, 2013)

\section{Efectos del euro}

Semejante cambio debe ser correctamente dimensionado en sus justas proporciones. Por ahora, basta acotar que un acto económico de tal significación solo terminará de ser plenamente entendido luego del paso de varios lustros, como la más autorizada doctrina académica, iterativamente lo ha mencionado (Zeppernick, 2002). Por lo tanto, las opiniones sobre los efectos, bondades y problemáticas de su introducción difieren profundamente, y bueno, tal vez haya que recordar aquí la lucidez del adagio de los abuelos, según el cual "cada quien habla, según como le va en la fiesta". Y es que en las más agudas críticas de cada país europeo contra el nuevo sistema monetario, se termina vislumbrando-como es apenas natural- una propensión al análisis de las problemáticas nacionales e incluso locales.
De las así llamadas ventajas "puramente económicas"

La ventaja más importante de la introducción del euro, incluso el objetivo mismo perseguido conesa medida por la Unión, era la reducción de los riesgos provenientes del tipo de cambio y la facilitación de la inversión a través de las fronteras respectivamente. (Euroinphoto.eu, 2013)

Las fluctuaciones de las tasas de cambio, históricamente han sido la mayor causa no solo de la eliminación contable de las ganancias en los mercados transnacionales, sino de la crisis de ciertos sectores económicos importadores o exportadores, respectivamente (Rojo, 2009, p. 507 ss.). Al diluir el riesgo o al asegurarlo, desaparecen los sobrecostos en el mercado financiero. Invertir, negociar, desplazarse inclusive, sin esos riesgos, resulta pues más atractivo, aun desde el punto de vista jurídico. Históricamente se ha demostrado que el mejor método para lograr esos objetivos es la imposición o la unificación monetaria, respectivamente. Por supuesto, de lo anterior fluye casi automáticamente la eliminación de los costes derivados de las transacciones bancarias entre divisas. $\mathrm{Y}$ ya que el grueso de la balanza de la economía europea pende de las "exportaciones e importaciones" nacionales -valga aclarar- en el interior de la misma Eurozona $^{6}$, los beneficios no deben ser pues subestimados. Es evidente que se ganó

$6 \quad$ La Eurozona o Zona euro es el conjunto de estados miembros de la Unión Europea que han adoptado el euro como moneda oficial (actualmente se compone de 17 Estados), formando así una unión monetaria. Su creación data del 1 de enero de 1999. La autoridad monetaria que controla la eurozona es el así llamado Eurosistema. 
gran flexibilidad y liquidez en los mercados financieros, reflejadas fundamentalmente en un incremento en la competencia y disponibilidad de productos bancarios de fácil accesoen los países de la Eurozona. A su vez, los costos inmanentes a la deuda pública disminuyeron considerablemente. (Duwendag et al., 1999, p. 8 y ss.)

Descendiendo al sector real hay que mencionar que el comercio y el trabajo empresarial y particular conjunto se vieron fortalecidos. Proyectos como el Airbus A380, que hoy en día compite en igualdad de condiciones con las empresas americanas del sector y que se constituyó en un momento dado, sin duda alguna, como símbolo de la pujanza de la economía europea, o los programas de exploración espacial europeos, no habrían sido posibles sin la unidad monetaria. Entre los años 2002 y 2007 el comercio interior de la Eurozona se incrementó entre un 5 y un $15 \%$ de manera diferenciada para diversos sectores. En general, para las empresas europeas -otrora nacionales-, poder agenciarse mercantilmente en una zona de semejantes dimensiones, como la Eurozona, con las seguridades absolutas mencionadas, se constituyó, desde luego, en una gran ventaja (European Central Bank [ECB], 2011).

El Banco Central Europeo ha cumplido a cabalidad su tarea de prevenir y eliminar la inflación. Si bien es cierto que el objetivo de mantenerla por debajo del $2 \%$ no ha sido alcanzado en todos los periodos ni en todos los países, no lo es menos que desde una perspectiva puramente económica, el argumento de que se ha logrado exitosamente, que los puntos de exceso por encima de ese límite impuesto, hayan sido mínimos, se ha constituido en un caballo de batalla prácticamente incontrovertible en el mismo medio económico, atendidas las considerables dimensiones de la Eurozona y la relativamente reciente creación del mismo mercado (European Central Bank [ECB], 2011).

Hubo un tiempo, hasta el año 2007, en que especulaciones de otras monedas contra el euro, que atemorizaran a la comunidad, resultaban impensables debido a su estabilidad, a su fortaleza, a las reservas nacionales que lo respaldan, sobre todo en el llamado "eje francoalemán", y fundamentalmente por el tamaño de su mercado. Incluso se logró que la sinonimia creada alrededor del mundo desde los años treinta del siglo pasado, por la economía política, entre las palabras "dólar" (americano) y "divisa", fuera historia. (Krugman\& Wells, 2007, p. 470 y ss.)

Algunas especulaciones monetarias de esta época, le merecieron duras -pero desde mi punto de vista, infundadas-, críticas al sistema monetario unificado europeo, como la llamada crisis de la libra esterlina y la crisis asiática. Estimo que ha de reconocerse -incluso por el contrario- que por la diversificación de reservas de muchísimos países, las economías nacionales dependieron menos de la latencia de un dólar 
altamente volátil y en alguna medida "no"previsible, de suerte que en cierta manera se ha causado una mayor estabilidad en las economías internas de las naciones que así diversificaron sus reservas.

\section{Ventajas políticas}

En ese mismo sentido, ya en el panorama mundial, no debe subvalorarse el significativo ascenso político-económico que la unificación monetaria le representó a Europa, tanto en el escenario internacional, como en la geopolítica mundial. Se admitiría que la paz, galardonada con el ya no tan reciente Premio Nobel ${ }^{7}$, se materializa, entre otras muchas ventajas, por la posibilidad económica de coordinar más proyectos económicos fuera de la Unión, lo cual se derivó básicamente de esa unidad económica. La voz de Europa en cuestiones económicas debe ser escuchada en creciente medida; más hoy en día, cuando ha sido la solvencia del euro, la que ha soportado la mayor parte de la crisis financiera, desde los últimos meses de 2008. Dentro de los tres poderes económicos que actualmente lideran el mundo, es la Eurozona -en parte gracias a la introducción del euro- el mercado más estable y con un mayor equilibrio entre los asíllamados sectores real y financiero. Problemáticas como el colapso del sistema financiero norteamericano o las deplorables condiciones laborales que tratan de acallarse desde China, desbordan el preciso objeto de este estudio. (Lindberg, 2009, p. 112 y ss.)

También desde el punto de vista político, basta decir que se tiene al euro como la gran consolidación del Mercado Común, en el que ya el tráfico libre de productos, servicios, personas y capital había sido alcanzado, de manera modesta, pero incluso previa a la suscripción del Tratado de Maastricht.

\section{Ventajas jurídicas}

De otro lado -y aquí es donde radica mi mayor interés, dentro del marco de mis investigaciones atinentes a la realización plena de los derechos sociales, económicos y culturales- huelga reconocer que en el sector real, el euro antes de 2008, había permitido una mayor y más ágil igualación de las condiciones de vida de la población europea. El jalonamiento de los países miembros altamente industrializados de la Eurozona (Alemania, Francia, Austria y Holanda), implicó para los demás países un mejoramiento sustancial de esas mismas condiciones de vida, luego de la introducción del Euro y de sus políticas de igualación. Durante el periodo de 1992

\footnotetext{
Umberto Eco y Tonyt Judt, por ejemplo, entre otros muchos académicos, en artículos más periodísticos que académicos, valoran desde un punto de vista político, la unidad europea y sobre todo, la paz alcanzada en ese continente; lo que ha implicado muchas ventajas, no solo para los europeos, sino para el mundo entero. La sola finalización de la guerra fría ha implicado un mundo más tranquilo. Véase, al respecto, por ejemplo: Eco (2013) o el libro de Judt, titulado Algo va mal.
} 
a 2007 se hizo pues palpable el mejoramiento del cumplimiento de los llamados derechos de prestación del Estado.

Por mencionar solo un par de ejemplos:

- En el ámbito social puede decirse que se pusieron mayores recursos a disposición de prestaciones estatales como el seguro de desempleo en toda la Eurozona, lo cual solo comenzó a ser desmontado en el año 2010, inclusive.

- En el campo cultural se han fortalecido programas que antes eran muy incipientes enel ámbito universitario, como el programa "Erasmus" que recibe su nombre de la alusión al gran humanista Erasmo de Rotterdam, y que fundamentalmente promueve la formación integral del estudiante universitario europeo, al dotarlo de movilidad a lo largo y ancho de todos los países y lenguas de la Unión Europea actual.

\section{Desventajas políticas y económicas}

Sin embargo, resulta claro que consolidar un mercado de semejantes proporciones no es tarea fácil. Algunos economistas siempre se mostraron escépticos y habría que reconocer que recientes problemáticas como el sobreendeudamiento público y la inestabilidad de países como Grecia, Irlanda, España, Italia y ahora Chipre, justificaban sus temores.

Poco a poco la diferencia de precios de bienes y servicios en la Eurozona se fue disminuyendo a través del llamado "arbitraje económico geográfico", que, entre otras cosas, fue el más grande, complejo y polifacético que haya conocido la historia de la humanidad. Así, los mismos productos y servicios en el interior del mercado común tuvieron precios muy diferentes en cada país, como consecuencia de la conversión de las monedas nacionales al euro. Esas diferencias debían ser eliminadas lo más pronto posible. Su igualación conduciría a una competencia más fuerte y diversa entre los oferentes y consecuentemente a una menor inflación, y, en principio, a mayor bienestar y prosperidad para los consumidores. La actividad mercantil derivada de la divergencia de precios de un bien en diferentes mercados, geográficamente entendidos, o, por el contrario, la especulación por la baja de precios temporal, que trataban de ser aprovechadas por algunos, eran pues -o lo son aún hoy- eliminadas a través del arbitraje económico. Así, se toman medidas simultáneamente tanto en el sitio de los precios más bajos o de los precios más altos por parte de la Comisión Europea, el Banco Central Europeo y sus delegaciones en cada país adherente al acuerdo monetario (European Central Bank [ECB], 2011).

Entre los arbitrajes de efecto: el de valores, el de intereses sobre el dinero, el de inversión de capitales y el mal llamado arbitraje entre divisas, tuvieron una importancia protagónica en la estabilidad inicial del Mercado Unitario, luego de la introducción del Euro en los 
doce iniciales países ejecutantes de esta política monetaria.

A pesar de los denodados esfuerzos, es menester reconocer que una unidad monetaria para una zona económica tan grande y heterogénea, especialmente en cuanto a lo que se conoce como ciclos coyunturales asincrónicos que no pudieron ser superados por algunos países, como lo muestra el caso griego o chipriota, nunca dejaron de crear una cierta preocupación en el campo de la política monetaria conjunta.

Otro coyuntural problema se presenta por la fijación de entrada en el tiempo de las economías nacionales. Específicamente por la fijación del cambio de curso de momento. Una economía nacional sobrevalorada que ingrese a la unión monetaria del euro, está entrando comparativamente con un mayor patrimonio, por supuesto asumiendo también mayores costos, precios e impuestos (p. ej. Francia), que otros Estados con una economía subvalorada en números o equivocadamente sobrevalorada en el sector real (p. ej. Grecia) o en realidad subvalorada (p. ej. Italia). Una igualación a favor de los Estados con patrimonios sobrevalorados se pensaba al principio, en la práctica, solo como difícilmente alcanzable y hoy en día como definitivamente imposible ${ }^{8}$.

En las economías subvaloradas, el bajo estímulo adicional a la importación en virtud de los altos precios en otros países de la Unión, produce deflación. Ello trae, entre otros muchos efectos, paulatinamente, un asentamiento de la pequeña y mediana producción en los países miembros que tienen costes laborales más favorables, fundamentalmente mano de obra y materias primas más baratas. A su turno, el problema macro de cada economía nacional es muy difícil de solventar, pues depende en gran medida de la capacidad y la intención de inversión privada.

Resulta dudoso incluso que el Banco Central Europeo y la Comisión Europea puedan mantener a los Estados miembros en cintura, sobre todo a aquellos que están temerosos de cumplir con las reglas fiscales, a la hora de hablar de nivelación de déficit de la Hacienda Pública o comunal. En caso de que alguno de ellos pierda el control -como parece que ocurrió con Grecia, España y Chipre-, si no se producen las correcciones adecuadas a tiempo, como ya lo vimos, ello podría reconducir a pérdidas significativas en la calidad de vida de la población del respectivo país y lo más grave -desde el punto de vista económico-a una fuga que produciría la precipitación del euro en la economía mundial: como es bien conocido, algunos dicen que el problema puede darse por superado, otros que la caída del euro es solo una cuestión de tiempo.

Independientemente de la crisis, cada año, debían y deben pues producirse las

$\overline{8}$ Basicamente, porque las reglas de disciplina fiscal ya no se pueden cumplir a cabalidad. 
llamadas en alemán, "igualaciones unísonas". Antes de la crisis de 2008, mientras que los así llamados "países pigs", en la jerga económica (para aludir jocosamente a las iniciales de Portugal, Italia, Grecia y España), presentaban un promedio de crecimiento de $-1 \%$; en Irlanda había promediado un $1,3 \%$ y en Alemania un 2,9\%. Estas considerables diferencias evidencian que las arraigadas cotas regionales no se dejan pues mitigar suficientemente de manera oportuna, solo con una diplomática política monetaria unificada desde Bruselas y Berlín.

\section{Desventajas jurídicas: puntos de contacto entre el euro y el consumidor}

Con la introducción del euro a un mercado constituido por 320 millones de personas, muchos de sus consumidores últimos se sintieron afectados, en la medida en que se verificó un encarecimiento de bienes y servicios; y es en este punto donde es menester extrapolar de acuerdo con las teorías económicas clásicas, al producto por antonomasia: al dinero, que en el caso de la Unión Europea se materializa en el euro, y al HomusOeconomicus del que ya arriba he hablado, y que para la Unión se materializa en el particular consumidor del mismo mercado común.

Podrían ubicarse puntos de contacto entre el circulante económico por excelencia y el sujeto determinado del mercado, en dos momentos: la tributación impuesta por los Estados miembros, que quedó sin ninguna clase de regulación supranacional, y los ordenamientos constitucionales que mitigan o incluso solucionan los descalabros económicos. Estos dos escenarios se desarrollarán más adelante.

\section{EL CONSUMIDOR EN EUROPA}

Así como el euro ha sido un factor determinante del nuevo protagonismo de Europa en el panorama mundial económico globalizado, es también necesario destacar que en el interior de las fronteras de la Eurozona, de todas las políticas económicas, la que atañe a la defensa del particular inmerso en el mercado, ha logrado establecer un entendimiento nuevo y diverso de la economía.

Como ya ha quedado sugerido antes, la abstracción del demiúrgico binomio "individuo-dinero", que conlleva la concreción europea actual y que se traduce en un nuevo par "consumidoreuro", se ha vuelto también una realidad cotidiana solo a partir del año 2002 en toda la Unión, a través de diversas instituciones creadas también por la Unión Europea. El individuo debía ser entendido de manera diversa dentro del mercado común. Esta apreciación, si bien ha sido discutida desde diversas ópticas (Von Vogel, 2006, p. 39-47), tiene su peso definitivo en tanto no podría concebirse un mercado común de semejantes dimensiones, sin unas regulaciones específicas que protegieran a quien de manera prácticamente peligrosa quedaría sometido a las reglas económicas, que un ominoso mercado prácticamente inmanejable, podría imponerle (Von 
Vogel, 2006, p. 32-39; Beater, 2000, p. 31). En términos ius-filosóficos, la creación de un mercado de semejantes dimensiones, que atravesara fronteras, lenguas y culturas, presupuso la creación de un nuevo entendimiento del sujeto, en términos jurídicos, pero también económicos.

Las medidas más destacadas al respecto, tienen que ver con la protección que a través de las regulaciones contenidas en las respectivas directrices, se ha otorgado al consumidor frente a la empresa, a la hora de perfeccionar los contratos y que pueden enumerarse, de manera concreta como: el derecho de revocación en negocios celebrados en la puerta de la casa (o por fuera del establecimiento de comercio, como otros las han llamado), en los contratos celebrados a distancia, el respeto por las obligaciones en el tráfico jurídico negocial electrónico, y en el derecho de revocación y poder para la revocación, que están contenidos en sucesivas y claras directrices que desde 1984 venían tratando de proteger cada vez más derechos del consumidor. Esas directrices han sido debidamente trasplantadas por cada país miembro a su propia legislación y son aplicadas, como derecho comunitario, directamente por los jueces de cada uno de los mismos ${ }^{9}$.
De otro lado, la implementación generalizada y amplia de la teoría de las cláusulas generales de contratación dio un mejor y más amplio fundamento a la revisión judicial a posteriori de la verdadera paridad contractual cuando interviene un consumidor y una empresa ${ }^{10}$. En Alemania, la trasplantación de las respectivas directrices se materializó con la incorporación de varios nuevos parágrafos en el Código Civil, que modifican la interpretación de las declaraciones de voluntad, a la hora de hablar de la configuración de las relaciones obligacionales; negocios jurídicos que incorporaran condiciones generales de contratación ( $\S 305$ - 305a - 310 BGB). La introducción se perfiló como la Schuldsrechtsreform del año 2002 o la reforma del derecho de obligaciones en el Código Civil alemán.

La realización de los derechos de los consumidores se vio también perfilada por la posibilidad de acceder a créditos de consumo y a una serie de prestaciones estatales que daban cuenta de una visión mucho más omnicomprensiva de los derechos económicos sociales y culturales en toda la Unión, como la vivienda, la educación o la salud. Los estándares de altísima calidad en cuanto a la educación y la salud, permitieron en determinado momento obtener prestaciones muy significativas por mesurados precios. (Fuchs, 2011, p. 9-22)

\footnotetext{
$9 \quad$ Para consultar las dos directrices más importantes: 85/577/ EWG, 97/7/EG, se puede acceder a: http://eurlex.europa.eu/LexUriServ/LexUriServ.do?uri=CELEX:31985L0577:de:HTML y http://ec.europa.eu/consumers/ policy/developments/dist_sell/dist01_de.pdf respectivamente.

10 Directriz 93/13/ de la Comunidad Europea.
} 
Pero más allá de las medidas mencionadas, el Comité Económico y Social Europeo, más conocido por sus siglas en español CESE, es uno de los órganos dedicados a articular la nueva concepción jurídica del sujeto en el marco de la Unión, con otros fenómenos de los demás subsistemas. Y es que si han de contemplarse las nuevas formas de división del poder o los acoplamientos políticos recientes, que a la fuerza le impone la globalización a Europa, no puede dejar de mencionarse al Comité, que a través de sus asesorías sirve de canal intercomunicador entre las poderosísimas instituciones intergubernamentales de la UE, sus empresas transnacionales por las que fundamentalmente fluye capital privado y lo que dio en llamarse a mediados de los años ochenta, la "sociedad civil organizada".

Sus miembros representan a una comprensiva diversidad de intereses económicos, sociales y culturales de los países miembros y grosso modo han sido clasificados en tres categorías: "Empresarios, trabajadores y actividades diversas". Esta última incluye a los campesinos, a los ecologistas, a los tipos de familias europeas, dentro de los cuales, vale apenas mencionar, entre otras interesantes particularidades, la defensa que se adelanta por ejemplo, a favor de la conservación de las culturas de los gitanos y los Yöruk, o tribus nómadas de los Balcanes. Por supuesto, un alto porcentaje de sus miembros representa también a los consumidores que día a día, ganan mucho terreno a fuerza de evidenciar y querellar sus derechos frente a la poderosa estructura estatal de la Unión.

\section{El consumidor como categoría jurídica}

Así pues, tanta fuerza ganó la que para entonces era apenas una recién reconocida clasificación económica en el Tratado de Roma, que incluso se asentó una nueva categoría jurídica que ya para finales de los años 70 (Verbraucherzentrale Hessen, s.f.) produjo una serie de normas que, paulatinamente, desdibujaron el axioma decimonónico de la igualdad de los contratantes promovida por el derecho civil: el derecho a la protección del consumidor.

Para expresarlo de manera ilustrativa, si tenemos en cuenta los marcos de lucha política de referencia de los que se ha valido el materialismo histórico para describir el permanente conflicto eurocentrista, y que desde una perspectiva puramente jurídica esbozó el Gran Rodolfo de Ihering, en uno de sus más bellos opúsculos, La lucha por el derecho, a los ya habituales binomios amo y esclavo, señor y siervo, monarca

11 Preceptúan las normas recién mencionadas: § 13) Consumidor. Consumidor es cada persona natural que concluye un negocio jurídico con una finalidad, que no puede ser atribuida ni para su empresa, ni para su actividad profesional autónoma. § 14) Empresa. Empresa es una persona natural o jurídica o una sociedad personal con capacidad negocial, que negocia la conclusión de un negocio jurídico en ejercicio de su actividad empresarial o profesional autónoma. Una sociedad personal con capacidad negocial es una sociedad personal que está dotada con la capacidad de adquirir derechos y obligaciones. 
y un burgués, Estado de derecho y ciudadano, patrón y trabajador, tal vez habría que agregar un nuevo duplo del que ya dan cuenta no solo la normatividad europea del consumo, sino incluso los parágrafos 13 y 14 del Código Civil alemán ${ }^{11}$, innegable baluarte de la precisión jurídico-científica europea, desde el año 2002: "el consumidor y la empresa".

Ello ha conducido a que dentro de los grupos de influencia que tras los partidos se enfilan, junto a los sindicatos, las asociaciones de trabajadores, los grupos económicos y demás organizaciones de intereses, junto a los medios de comunicación, inclusive, deba reconocerse una fuerza política adicional, que terminó configurando no solo la forma de los Estados nacionales, sino algo más profuso y complejo todavía: la misma Unión Europea, a través de su propio y común mercado y desde una perspectiva, o mejor aún en la descripción luhmanniana de la sociedad, desde el subsistema jurídico, que ya desde los años cincuenta esbozó una muy particular forma de concebir todo el derecho privado: los consumidores.

Ahora bien, obviados un par de fracasados intentos ingleses, el verdadero nacimiento de una concepción política en pro de la defensa unificada del consumo, puede ser ubicado temporalmente con la fundación de la asociación de amas de casa católicas alemanas en el año de 1903 [Gründung der Hausfrauenvereinigung des Katholischen Deutschen Frauenbundes] (Verbraucherzentrale Bundesverband, 2011).
En efecto, esas asociaciones pueden ser catalogadas como las primeras fundaciones de asociaciones de consumidores emparentadas a concepciones políticas partidistas, así como una verdadera aspiración política de crear una normatividad que buscara la defensa de una parte contractual en la celebración de negocios masivos, concluidos por las personas naturales, frente a una organización económica, independientemente tanto del valor del negocio celebrado, así como de las dimensiones o las calidades de la empresa oferente de productos, y que fungiese como contraparte negocial.

En realidad, haciendo justicia a la historia, es menester reconocer que desde la expedición del BGB (Código Civil de Alemania), se puso especial mesura en la determinación de la desigualdad o igualdad de los contratantes por la comisión redactora; y no siendo ello suficiente-como es por todos conocidoOtto Von Gierke, entre otros, dedicó varios de sus críticos estudios a analizar la falta de reconocimiento de muchas formas de contratación peligrosa para el ciudadano particular, por parte de la ya temprana reinterpretación jurisdiccional del mismo código (Gierke, 1895).

No es veraz entonces predicar apenas un reciente cambio en la concepción del derecho privado alemán.A lo sumo tergiversan la historia, quienes quieren así entenderlo, pues fueron también fenómenos políticos de profunda significación los que generaron ya vanguardistas tesis sobre la 
interpretación contractual de los derechos en el interior del Reichgerichtshof o Tribunal imperial en la década de 1920 en Alemania. Las cruentas condiciones sociales desembocaron entre otros efectos, en lúcidas creaciones jurisdiccionales que -hijas de su tiempo- permitieron la racionalización del mercado y la protección del particular como objetivo último. Las dos conflagraciones mundiales fueron causa eficiente del nacimiento de teorías de creación judicial [Richterrechtliches $R e c h t]$, que por vía de la teoría del ejercicio abusivo de los derechos y el deber de cumplir con la prestación negocial de buena fe, preceptuadas en los $\$ \S 226$ y 242 del $\mathrm{BGB}$, materializaron figuras como la teoría de la imprevisión contractual, el reconocimiento de la patente inferioridad de una parte negocial o la culposa omisión de información durante las etapas precontractuales, como fuentes de derecho. Esas instituciones, mal o bien calcadas, son perfectamente reconocibles en las directivas redactadas por parte de la Unión Europea durante los años noventa.

Como gran corolario de ese conjunto de normas se deduce que las más apremiantes necesidades de las personas naturales y su incontrovertible ejercicio de la libertad, por supuesto no pueden ser aplazados en atención a la observancia absoluta de las formas económicas o jurídicas (Sen, 2000). El derecho y el mercado son apenas medios emanados de la sociedad y puestos a su óptima utilidad; no son, ni pueden ser, una finalidad por si misma considerada. Contrario a ello, pareciera cobrar fuerza nuevamente la afirmación kantiana de que la dignidad del hombre es el objetivo en sí mismo considerado y que tal entendimiento de cosas, no solo ha quedado plasmado en la frase primera del párrafo primero del artículo primero dela Ley Fundamental de Bonn, sino que se ha diseminado en todos los niveles del ordenamiento jurídico alemán y a su turno -en buena hora- ha permeado la concepción política y jurídica misma de toda la Unión Europea.

Es ello lo que claramente se evidencia de una rápida lectura de las directivas 85, 87, 93, 94 y 97 emanadas tanto del consejo de la Comunidad Económica, como del Parlamento de la Unión, expedidas entre los años 1985 y 1998 y que se refieren a la protección del consumidor, como ya ha quedado referido. Una circunstancia temporal significativa, como es sabido, para este análisis, es que cada uno de los países miembros de la Unión Económica estaba obligado a hacer la trasplantación de la respectiva normatividad,contenida en las directivas de consumo, a su propio ordenamiento jurídico privado, a más tardar de manera simultánea a la entrada en vigor de la unificación monetaria en pleno.

En ese contexto, la reforma del derecho de obligaciones del Código Civil alemán del año 2002 provocó muchas expectativas. Alemania, de manera contraria a lo que decidieron otros países miembros, no expidió un código del consumo ni una ley para los consumidores, sino que introdujo la 
normatividad europea sobre consumo en su Código Civil. Desatendidas justas críticas de la doctrina nacional alemana (Rüthers, 2011), si bien es cierto que el BGB puede haber perdido parte de su sistemática, no lo es menos que el derecho del consumo alemán perfilado ya desde 1970, la ganó en una fuerte dosis, pues el descarte o la inclusión de derechos de una parte negocial, que debe ser entonces entendida como consumidora, se ha tornado en un elemento más del famoso análisis esencial de cada declaración de voluntad o análisis jurídico conceptual, de la ciencia jurídica en la República Federal de Alemania (Rüthers \& Stadler, 2011).

Con todo, es necesario admitir que las regulaciones europeas sobre consumo no han sido perfectas. De las prerrogativas más poderosas concedidas al consumidor último, la del derecho de devolución del producto adquirido ha sido fuertemente criticada, ya que incluso llegó a poner en jaque la economía de consumo de algunas regiones alemanas, durante el año 2005 (Spiegel Online, 2005). Así, luego de un único uso fueron devueltos no solamente electrodomésticos de considerable valor, sino costosas prendas de vestir, joyas, e incluso vehículos y carísimas cuotas de tiempo compartido en inmuebles vacacionales. Sin embargo, la Sala Civil del Tribunal Supremo Federal hasta diciembre del año 2009 se mantuvo incólume en su posición de traslado del riesgo de la negociación contractual a la empresa y consecuentemente de absoluto apoyo al consumidor, incluso cuando éste ha tratado de ocultar su verdadera identidad, a través de una cuenta ficticia en las redes de compra y venta electrónicas como "eBay"; lo que en últimas -en sentir del tribunal- no pervierte su calidad de persona natural y por ende de consumidor último (Jurpc, 2009).

\section{ARTICULACIÓN JURÍDICA DEL ENTENDI-MIENTO DEL EURO CON LA NOCIÓN DE “CONSU- MIDOR"}

Ahora bien, surge una pregunta: ¿es viable articular dos temas que hasta ahora parecen tan ajenos como la política monetaria de la Eurozona con la noción de consumidor que se ha expuesto?. Al respecto, vale anotar que no solo es viable articular esos dos fenómenos desde perspectivas ajenas a lo económico, sino que ello es necesario a efectos de entender cabalmente la actual configuración política europea y la discusión ético-política que parece perfilarse.

Desde el punto de vista jurídico podría decirse que euro y consumidor se articulan entre muchas posibilidades, por lo menos en dos momentos claramente reconocibles y decisivos a la hora de posibilitar el funcionamiento de la Unión.

EI consumidor como contribuyente: su percepción en el estado actual de cosas en Europa

Un momento que he llamado ex ante es aquel que tiene que ver con la 
configuración tributaria de los particulares. Moneda y persona natural se dinamizan entonces por la ejecución de las políticas tributarias de cada uno de los países miembros, y aquí vale la pena hacer varios reconocimientos importantes, pues la austeridad no ha sido un común denominador para todos los países miembros de la Eurozona y aparentemente haber dejado de manera aislada la tributación a cada uno de los gobiernos nacionales sin hacer ajustes previos, tal vez pudo no ser del todo prudente.

Las diferencias entre políticas tributarias son claramente reconocibles. Mientras en Grecia se alegó por parte del gobierno de GiorgiosPapandreu que el acceso a la burocracia prometida por los partidos en campaña, "no puede ser un derecho para cualquier ciudadano", desde Alemania el ministro de Hacienda se pregunta desde 2008, permanentemente “¿por qué el trabajador y juicioso contribuyente alemán, (léase también como "el consumidor"), debe correr con la indemnización de los daños generados por sus homólogos griegos, españoles, italianos o chipriotas?"

La buena fe del particular, la corrección que desde los tiempos de los romanos se objetivaba con el ideal comportamiento de un buen padre de familia y hoy en día con la de un buen hombre de negocios, cobra una trascendencia considerable entonces y fundamentalmente para reconocer no solo arraigadas diferencias culturales, sino diversos tipos de consumidores, de contribuyentes y de políticas en cada una de esas áreas en el interior de la Eurozona. El inveterado concepto de la confianza legítima con la que unos particulares concurren a un mercado vuelve a tomar una inusitada importancia a la hora de evidenciar que la plurilateralidad de esas esperanzas es un presupuesto del que no solo, de manera errada, no se partió para admitir el ingreso de cada nuevo país al acuerdo monetario, sino que es la base sobre la que la permanencia del mismo país como miembro del euro pudo, puede y podrá afianzarse.

De otro lado y como lo ha manifestado el profesor Paul Kirchhofex magistrado de la Corte Constitucional Federal alemana y una autoridad en cuestiones económicas, una de las ventajas de la separación de poderes de todas las democracias modernas que no se debe olvidar, es la imposibilidad de que el contribuyente se encuentre habilitado constitucionalmente para decidir directamente sobre la utilización de sus tributos. Esto es el recaudo hecho por parte de la Hacienda Pública de cada país, pues ello implicaría la inviabilidad económica misma de cualquier nación. El parlamento es entonces el órgano competente, eso sí -legitimado democráticamente- para fijar las directrices económicas y la cantidad de tributos que además, en últimas, determinan la verdadera capacidad adquisitiva del particular y consecuentemente el estatus de cada consumidor. En nuestro contexto, a través de esa prerrogativa ha determinado el Estado alemán, a través de su parlamento, e incluso a través de su 
ejecutivo, si vale la pena seguir girando rescates para las finanzas griegas, chipriotas o de los demás países europeos en crisis.

La decisión del Tribunal Constitucional alemán de septiembre pasado delimitó de manera estricta, nuevamente, la posibilidad de seguir respaldando la crisis griega que, entre otras cosas, ha evidenciado, que ese gobierno nacional fue en el pasado altamente negligente en la reducción de su gasto y en el manejo de sus políticas económicas (Spiegel Online, 2012). Incluso se ha barajado más frecuentemente la posibilidad de que Grecia voluntariamente o por presión de sus acreedores abandone la Eurozona, al obligarla a pagar cumplidamente, tan solo los intereses pactados de sus crecientes y costosas obligaciones adquiridas fundamentalmente antes de 2002.

Soluciones más plausibles sugieren una refinanciación de las deudas griegas a través de contratos de Swaps entre naciones y recompras de deuda, pero lo cierto es que desde una u otra perspectiva esas decisiones serán tomadas, más desde un enfoque político, que económico o incluso jurídico, a pesar de que en las dos áreas pareciera ser relativamente clara la solución al problema, pues como la canciller alemana lo ha manifestado en reiteradas ocasiones, las reglas del Tratado de Maastricht sobre la disciplina de cada país miembro son minuciosamente claras y no se podría sin más, tomar un camino diverso, en tanto que la puesta en vigilancia de la Hacienda griega por parte de la Comisión y el Banco
Central Europeo, fueron las medidas que según el acuerdo ya se tomaron en previsión de una posible exclusión de la balanza griega.

Esas consideraciones no impiden precisar que tanto en uno como en otro país de la Eurozona, son las élites políticas las que en últimas deciden la suerte de los dos fenómenos, no el particular que yace a la deriva de ciertas concepciones y contingencias como las que en Grecia observamos. Sin embargo, de Perogrullo resulta la afirmación de que la pertenencia a una comunidad brinda no solo derechos, sino que exige fundamentalmente deberes y compromisos.

\section{Los tribunales constitucionales: la herramienta para reparar los subsis- temas en la democracia posmoderna}

Ahora bien, el otro momento ex post, en el que consumidor y euro son estimulados desde lo jurídico, resulta ya no de las decisiones políticas del parlamento de cada país en elámbito tributario, aun en caso de que esos entes decidan desde Bruselas o Berlín librar un paquete de ayuda económica adicional a favor de Grecia, Chipre o España en los días venideros, sino de la decisión que los tribunales constitucionales respectivos tomen sobre eventuales controles o demandas. ¿Ha mentido el Estado griego o el Estado chipriota para ingresar al acuerdo económico? Ello sería un hecho imprevisto e imprevisible acaecido que podría implicar la expulsión del acuerdo hoy en día, aun a costa de la debilitación de la economía de 
los miembros restantes. ¿Deben ser nuevamente asumidas las deudas griegas por los contribuyentes, ergo por los consumidores del resto de los países de Europa, para sellar una mínima estabilidad que despierte una definitiva confianza de los inversores? El escepticismo es la única respuesta a esa pregunta, que sin embargo parece responderse afirmativamente desde todos los espectros políticos.

Sin embargo, la inconformidad de la población se ha hecho sentir de manera significativa en las protestas sin fin que se han desatado a lo largo y ancho de los países más afectados como Italia, Portugal, Chipre y sobre todo Grecia y España. La afirmativa salvación obligatoria provocaría, entre otras opciones, la interposición de múltiples demandas y quejas de grupos interesados como la que para esa eventualidad presentaron en Alemania los famosos economistas Hankel Nällinh Starbatty, asesorados por el jurista Albrecht, quienes han estimado desde siempre que la liberación de ayuda por parte de Alemania podría no solo violar los Tratados de Maastricht y Lisboa y por ende la Ley Fundamental, sino desencadenar una avalancha de solicitudes de los llamados países pigs, parecida a la que vivimos, con los miembros de la banca internacional en 2009.

En efecto, solo serán los tribunales constitucionales o políticos los que pondrán el sello final de concordancia o contradicción de cualquiera de esas decisiones, no solo con las propias constituciones nacionales, sino con los acuerdos estructurales de la Unión Europea, en este caso Maastricht y Lisboa, pues como también Kirchhof lo menciona, no se debe olvidar que antes que una Unión Monetaria, la Eurozona es (y fue) una unidad jurídica que implica el cumplimiento de reglas.

La solución más efectiva es poner a todos y cada uno de los países en cintura a la hora de exigir que el gasto público no pueda superar el $60 \%$ del producto interno bruto como lo sugieren los economistas expertos desde Frankfurt.

En caso de que ello no ocurra, como lo sugiere también Kirchhof, gracias a la democracia constitucional anclada en la Ley Fundamental, se cuenta con ese taller de reparaciones últimas que son los tribunales constitucionales, donde se regula y se oxigena jurídicamente la relación dinero-sujeto: euro-consumidor, a través de la adecuada e impuesta proporción de la ejecución de decisiones ya económicas, ya políticas, ya sociales, por fortuna y como acontece también ahora en nuestro país.

\section{A MANERA DE CONCLUSIÓN}

Si bien el derecho del consumo ha sido ya objeto de fuertes críticas a lo largo y ancho de la Eurozona, no lo es menos que por la inestabilidad de economías como Grecia y España lo es también el euro. Sin embargo, ninguno de esos dos procesos sociales parece susceptible de dar marcha atrás. Los Unity inputs de 
que hablaba Luhmann y que en el contexto al que me refiero son el euro y el consumidor, si bien no dividen el poder, sino que por el contrario lo concentran, sí se contrarrestan, -si ustedes lo quieren, se destruyen- el uno al otro como lo he tratado de evidenciar; si no desde escenarios legislativos, concretamente en cuanto al derecho tributario, por lo menos ya desde el taller de reparaciones de la democracia supranacional que encarnan los tribunales constitucionales de cada país europeo.

De las medidas que se adopten frente a la que parece ser una inevitable crisis "financiera posgriega", se derivarán no solo los precedentes para futuros paliativos de los países más rezagados de la Unión Económica, sino el grado de prevalencia que acompañará jurídicamente al consumidor particular frente a políticas económicas. El resquebrajamiento que por países se ha venido produciendo a ese respecto, no puede mantenerse por mucho tiempo. Pues si bien es cierto que Alemania ha privilegiado a su ciudadanía, los efectos de la crisis ya también empiezan a sentirse en sus estados federados más rezagados, como lo son los del este, y como lo informa la prensa de finales del año pasado.
Resulta claro que los contribuyentes últimos que coinciden económicamente con el concepto de consumidor-persona natural, deberán asumir una parte de los costos de la anunciada crisis y entendidos por supuesto como consumidores europeos: ¿Cuánto, cómo y hasta cuándo?, son las preguntas que quedan en manos de los líderes políticos europeos, ya que de minicrisis nacionales no se pueden sacar en claro posibles antecedentes, pero gracias al Estado constitucional, democrático y de derecho, las decisiones de esos líderes deberán ajustarse a las normas jurídicas que en últimas reconducen a la dignidad humana como objetivo último del ordenamiento.

Tal vez la política económica del euro en la Unión tenga álgidos puntos normativos por corregir, al igual que el poderoso derecho del consumo. Sin embargo lo que nos queda pues, es confiar en que el más duro asalto de todo el combate ad portas de nuestros días, termine bien para la economía europea, pero que siempre prevalezca la premisa kantiano-hegeliana, de que la dignidad del ser humano es un objetivo: el objetivo por sí mismo considerado de todo conglomerado social económica y jurídicamente regulado. 


\section{R eferencias}

Airbus. (2013). The success story of Airbus. Retrieved from http://www.airbus.com/ company/history/

Beater, A. (2000). Ver braucherschutz und Schutzzweckdenken im Wettwebers recht. Tübingen: Mohr Siebeck.

Buchter, H. (2012, 11 de oct.). USA: Der ganz große Unterschied. Zeit Online. Recuperado de http://www.zeit.de/2012/ 41/USA-Wahl-Florida-Armut-Reichtum

Comité Económico y Social Europeo-CESE. (s.f.). A citizens-orientated approach to the Single Market. Retrieved from http://www.eesc.europa.eu/resources/ docs/qe-30-12-329-en-c.pdf

CVCE (2012). L'échec d'Euratom. Recuperado de http://www.cvce.eu/ collections/unit-content/-/unit/ 02bb76df-d066-4c08-a58a-d4686a3e68ff/ 957de4a8-4422-4e8f-9194-ebf39fdf7065

Diario Oficial de la Unión Europea (s.f.). Versión Consolidada del Tratado de la Unión Europea. Recuperado de http:// eur-lex.europa.eu/Lex UriServ/ LexUriServ.do?uri=OJ:C:2010:083:0013: 0046:ES:PDF

Diekman, F. \& Demling, A. (2012, 23 de oct.). Zweifel an EU-Statistik: So wird Deutschland arm gerechnet.Spiegel Online. Recuperado de http:// www.spiegel.de/wirtschaft/soziales/ statistik-zu-armut-und-sozialerausgrenzung-verzerrt-die-wirklichkeit-a862962.html
Duwendag, D. (1999). Geldtheorie und Geldpolitik in Europa: Eine problemor ientierteEinfuhrungmiteinemKompen diummonetarerFachbegriffe. Berlin: Springer.

Eco, H. (2013, 30 de marzo). En busca de un héroe. El Espectador. Recuperado de http://www.elespectador.com/opinion/ columna-413109-busca-de-un-heroe

Euroinphoto.eu (2013). Der Euro Geschichte und Bedeutung. Recuperado de http://www.euroinphoto.eu

Euro-Krisenländer weisen hohe Haushalts defizite aus. (2013, 22 de abril). Frankfurter Allgemeine. Recuperado de http://www.faz.net/aktuell/wirtschaft/ europas-schuldenkrise/wegenrezession-euro-krisenlaender-weisenhohe - hau shalts defizite - a us 12157863.html

Fuchs, M. (2011). Sind Prinzipien und Techniken des Verbraucherschutzrechts im Sozialrecht anwendbar? en Verbraucherschutz im Sozialrecht. Berlín: Lit Verlag.

Gierke, O. (1895). Deutsches Privatrecht. Leipzig: Duncker \& Humblot.

Handelsblatt. (2011). Klage gegen eurohilfen"das euro-abenteuer geht zu ende". Recuperado de http://www. handelsblatt.com/politik/deutschland/ klage-gegen-euro-hilfen-das-euroabenteuer-geht-zu-ende/4575850.html

Jurpc. (2009). Recuperado de http://www. jurpc.de/rechtspr/20090102.htm 
Kaiser, S. (2011, 28 de junio). Steuerkonzept: Wer von Kirchhofs Plänen profitiert - und wer nicht. Spiegel Online. Recuperado de http:// www.spiegel.de/wirtschaft/soziales/ steuerkonzept-wer-von-kirchhofsplaenen-profitiert-und-wer-nicht-a771115.html

Krugmann, P. \&Wells, R. (2007). Introducción a la economía, macro economía. Barcelona: Reverte.

Lindberg, L. N. (1963). The political dynamics of European economic integration. Stanford, Calif: Stanford University Press.

Luhmann, N. (1998). Social Systems. In Zeitschrift, Human Studies. Geistes un Sozialwissenschaften, Recht. Volumen 21, 2. Netherlands: SpringerVerlag.

Mises, L. (1953). The theory of money and credit.New Haven, Conn.: Yale University Press. Retrieved from http:// mises.org/books/tmc.pdf

Parsons, T. (1991). The social system. London:Routledge, Taylor \& Francis Group.

Rey, P. (2003). The economics of vertical restrains. In Stiglitz, J. E., \&Arnott, R. (2003). Economics for an imperfect world: Essays in honor of Joseph E. Stiglitz. Cambridge, Mass: MIT Press.

Rickens, C. (2012, 13 de enero). FrankreichHerabstufung: Der heilsame Schock. Recuperado de http://www.spiegel.de/ wirtschaft/soziales/frankreich herabstufung-der-heilsame-schock-a808948.html
Rojo, L.A. (2009). Fluctuaciones económicas y crisis recientes. Real Academia de Ciencias Morales y Políticas. [Online]. Recuperado dehttp://www.racmyp.es/ docs/anales/A85/A85-25.pdf

Rüthers, B. \& Stadler, A. (2011). Allgemeiner Teil des BGB. (16). Tübingen: C.H. Beck.

Sen, A. (2000). Desarrollo y libertad. E. Rabasco \& L. Toharia (trad.). Buenos Aires: Planeta.

Spiegel Online (2005, 27 de mayo). OnlineEinkauf: BGH stärkt Verbraucher rechte. Recuperado de http:// www.spiegel.de/netzwelt/web/ 0,1518,381956,00.html

Spiegel Online (2010, 13 de febrero). Debatte über EU-Wirtschaftspolitik: Juncker fürchtet Zerfall der Euro-Zone. Recuperado de http://www.spiegel.de/ w i r s c h a f t / s o z i a l e s / $0,1518,677689,00 \cdot \mathrm{html}$

Spiegel Online. (2012, 12 de sept.). Verfassungsrichter zu ESM: Karls ruhe genehmigt Rettungsschirm mit Vorbehalten. Recuperado de http:// www.spiegel.de/politik/deutschland/ karlsruhe-verfassungsgericht-lehnteilantraege-gegen-esm-ab-a-855298.html

Stöver, B. (2007). Der kalte Krieg, Geschichte eines radikalen Zeitalters: 1947-1991. München: C. H. Beck.

Verbraucherzentrale Bundesverband. (2011). Recuperado de http://www.vzbv.de

Verbraucherzentrale Hessen. (s.f.). Die Siebziger Jahre: Aufwertung der Verbraucherarbeit in Krisenzeiten. Recuperado de http://50jahre.ver braucher.de/1970-1979.html 
Von Vogel, A. (2006). Verbraucherver tragsrecht und allgemeines Vertrag srecht: Fragen der Kohärenz. Berlín: De Gruyter.

Zeppernick, R. (2002). Die Bedeuting des Euro für Europa und die Weltwirtschaft. Konrad Adenauer Stiftung Recuperado de http://www.kas.de/wf/doc/kas_368544-1-30.pdf?080708123058
Zorn, C. (2010). Zur Aktualität von Niklas Luhmann, Einleitung in sein Werk. Wiesbaden: VS Verlag für Sozialwis senschaften.

Zwiedineck, O. (1955). Mensch und Wirtschaft. Berlín: Duncker \& Humblot. 